\title{
Autonomía universitaria, su evolución histórica y sus retos ante el repliegue del modelo neoliberal
}

\author{
University autonomy, its historical evolution and its challenges \\ before the withdrawal of the Neoliberal Model
}

Autonomia universitária, sua evolução histórica e seus desafios

antes da retirada do modelo neoliberal

\section{OSWALDO ULLOA PEÑA ${ }^{1}$}

\begin{abstract}
RESUMEN
La Unesco ha propuesto una agenda de trabajo para el período 2015-2030 que se define a través de los 17 Objetivos de Desarrollo Sostenible en ellos las Instituciones de Educación Superior, organizaciones generadoras del conocimiento tienen una responsabilidad pública fundamental respecto a los contenidos curriculares, la ética y los valores que transmite. La reflexión sobre la contribución y responsabilidad social de las universidades implica una revisión a fondo de su misión. Dotadas de autonomía responsable y libertad académica que se ejerce en la cátedra y la investigación. Este artículo realiza una revisión histórica de la autonomía universitaria a lo largo de la historia, para determinar la responsabilidad social de la universidad, ante el nuevo contexto político y económico ante el repliegue del neoliberalismo.
\end{abstract}

Palabras clave: Autonomía; libertad de enseñanza; investigación, calidad de la educación.

\begin{abstract}
UNESCO has proposed a work agenda for the 2015-2030 period that is defined through the seventeen Sustainable Development Goals which the Higher Education Institutions, knowledge generating organizations; they have a fundamental public responsibility regarding the curricular contents, ethics and the values that it transmits. The reflection on the contribution and social responsibility of universities implies a thorough review of their mission. Endowed with responsible autonomy and academic freedom exercised in the chair and research. This article makes a historical review of university autonomy throughout history, to determine the social responsibility of the university, in the face of the new political and economic context before the withdrawal of neoliberalism.
\end{abstract}

Keywords: Autonomy; teaching freedom; research, quality of education. 


\section{RESUMO}

A UNESCO propôs uma agenda de trabalho para o período 2015-2030, definida através dos dezessete Objetivos de Desenvolvimento Sustentável. Nelas, as instituições de ensino superior, organizações geradoras de conhecimento; eles têm uma responsabilidade pública fundamental em relação ao conteúdo curricular, à ética e aos valores que ele transmite. A reflexão sobre a contribuição e a responsabilidade social das universidades implica uma revisão completa de sua missão. Dotado de autonomia responsável e liberdade acadêmica exercida na cadeira e na pesquisa. Este artigo faz uma revisão histórica da autonomia da universidade ao longo da história, para determinar a responsabilidade social da universidade, diante do novo contexto político e econômico antes da retirada do neoliberalismo.

Palavras-chave: Autonomia; liberdade de educação; pesquisa, qualidade da educação.

\section{INTRODUCCIÓN}

En nuestro contexto actual, hemos sido testigos de intensos y contradictorios cambios en el mundo. Los avances científicos, tecnológicos y sociales han reforzado las reflexiones para las transiciones de los países hacia las sociedades del conocimiento. El uso de internet permite un acceso a la información de vanguardia en tiempo real; se ha logrado un aumento en los niveles de escolarización. Se cuenta con ampliación de los espacios de participación social, política y cultural de la población; y existen espacios de trabajo permanentes para alcanzar los valores democráticos y los derechos humanos. Otros cambios han dado muestra de retraso y hemos observado inestabilidad mundial que impacta directamente en el bienestar de la población: crisis económicas cíclicas; polarización entre países; minorías privilegiadas frente a una creciente marginación social; pobreza; violencia; guerras; y cambio climático del planeta.

Las universidades, ante estos cambios económicos, sociales y laborales, tienen que implementar reformas acentuadas en sus modelos educativos y pedagógicos. Todos los modelos educativos en el mundo están incrementando cambios. Las variantes van desde la inferencia de estabilidad a la algarabía en el entorno; de la solidez de los conocimientos a la aceptación de su pronta obsolescencia; de la gestión rígida y disciplinaria a la flexibilidad e interdisciplinariedad; de la rutina a la creatividad y la innovación; del aprendizaje escolar al aprendizaje en los entornos sociales y productivos; y del pensamiento local al enfoque global.

A lo largo de la historia se ha debatido el tema de la autonomía universitaria, en muchos de los casos el debate sobre la autonomía, desde el enfoque político y financiero han sido el eje central del debate, sin embargo, en este artículo; nos referiremos a un análisis de mayor trascendencia, donde contamos con un mayor consenso sustentados en el siguiente planteamiento: la autonomía universitaria ha permitido a las sociedades del mundo avanzar en sus proyectos, en los momentos y contextos histórico sociales específicos. Esto se ha logrado gracias la función imprescindible de la universidad a través de la enseñanza y la investigación. 
El devenir de la humanidad depende en gran medida del futuro de nuestras universidades. Los saberes que se generan en las aulas y laboratorios no serían posible sin la existencia de la autonomía. El régimen interior de las universidades es su mayor fortaleza, porque es la vía para que los universitarios puedan incidir en todos los aspectos de la gestión académica y de la investigación.

Las universidades desde su origen se han constituido como un espacio de reflexión, donde estudiantes y docentes pueden dialogar y debatir sobre sus distintos enfoques, problemas, conceptos e ideologías. Esta acción es la que ha permitido generar conocimiento, resolver problemas y apuntalar a lo largo de la historia los grandes descubrimientos, conocimientos, obras artísticas, literarias e inventos.

La autonomía se ha conceptualizado como la libertad para diseñar los planes y programas de estudios, sin que, en tal diseño, donde siempre prevalece el espíritu académico, haya algún rasgo de injerencia de cualquier sujeto ajeno a la comunidad universidad. La libertad existe por la crítica y la crítica existe gracias a la libertad. Por tanto, preservar la autonomía universitaria, es necesario para lograr la educación de calidad para todos e incidir en el desarrollo sostenible.

Las universidades son el espacio para el desarrollo del pensamiento y la inteligencia. En el aula y el laboratorio debe construirse el desarrollo sostenible de una nación. La educación pública es el derecho universal de toda nación; y la autonomía permite que las universidades cumplan con su fin social que se define en los siguientes preceptos: "la adopción de estilos de vida sostenibles, los derechos humanos, la igualdad de género, la promoción de una cultura de paz y no violencia, la ciudadanía mundial y la valoración de la diversidad cultural; y de la contribución de la cultura al desarrollo sostenible" (Meta 4.7 del Objetivo 4 Desarrollo Sostenible) (Unesco, 2015).

La autonomía universitaria se describe con las siguientes acciones: conformar su propio gobierno, ejercer la función académica, de investigación y definir su ejercicio financiero. El primero de ellos permite que la universidad legisle sobre sus propios asuntos, se organice como le parezca mejor y elija a sus autoridades y al rector; según los estatutos que la misma universidad defina. El aspecto financiero permite la libre disposición del patrimonio que tiene la universidad, así como la elaboración y el control de su propio presupuesto (Marsiske, 2010).

La función académica en la autonomía universitaria implica que la comunidad universitaria puede: nombrar y remover a su personal docente según los procedimientos convenidos; seleccionar a los alumnos según los exámenes que ella misma aplica; elaborar sus planes de estudio; expedir certificados y títulos; entre otras de sus funciones principales. También garantiza la libertad de cátedra, cuestión que no se debe confundir con la autonomía misma.

Con el fin de contribuir al análisis y estudio sobre los retos actuales de la autonomía de las universidades, el propósito de este artículo pretende señalar la presencia de la autonomía como espacio para la gestión académica y producción de investigación, elementos que permiten generar cambios en el desarrollo de la ciencia y principalmente contribuyen en el desarrollo social y cultural de las naciones. Las decisiones políticas de los dirigentes a lo largo de la historia han visto, en ocasiones, a la universidad como un obstáculo para sus 
propósitos y proyectos, sin embargo; en este artículo pretendemos demostrar que la libertad de cátedra, la investigación y la autonomía, han permitido rectificar las decisiones de la clase política en turno, y han permitido construir el devenir de la humanidad.

Abordaremos este análisis histórico de los alcances de la autonomía en secuencia cronológica desde el origen del mismo concepto de autonomía como el espacio educativo de reflexión, iniciando con la obra de los filósofos griegos, a quienes consideramos los fundadores de la Educación Superior, para finalizar haciendo un análisis sobre el compromiso actual de la autonomía en las universidades ante el entorno actual de recesiones económicas, crisis de valores y el fracaso de la globalización bajo la concepción del neoliberalismo.

\section{La escuela en los griegos}

Sócrates, Platón y Aristóteles, filósofos clásicos inseparables y permanentemente criticando sus reflexiones, fueron grandes maestros que comunicaron sus saberes por medio de sus respectivas estrategias didácticas: mayéutica, dialéctica y diálogo de discusión científica, referido a su contexto histórico. La construcción del conocimiento se llevó a cabo en lugares específicos que eran espacios en los que se enuncian verdades que siguen siendo vigentes. La plaza pública en el caso de Sócrates, la Academia de Platón y el Liceo de Aristóteles fueron el origen de la educación superior: "Ese espacio, como un componente del proceso docente-educativo, se configura simbólicamente, es y a la vez significa, muestra y oculta algo, es un lugar donde habitan personas, un filósofo, el maestro por excelencia y sus discípulos, los ávidos por ser en el mundo" (Calderón \& González Agudelo, 2006).

La sólida propuesta de Platón al fundar la Academia en Atenas, en los terrenos del Jardín de Akademos, lugar donde los filósofos griegos se reúnen diariamente, según fuentes originales en el año 387 a. C. La Academia logra consolidar el esquema de una escuela pitagórica. Puede definirse como una cofradía científico religiosa con pretensiones políticas, que estudian preferentemente la geometría, creen en la preexistencia del alma, circulando siempre en distintos cuerpos y afirmando siempre que los temas de la ciudad solo pueden ser resueltos al gobernar los filósofos.

Los Diálogos de Platón son una obra literaria de gran aceptación, junto con la teoría Pitagórica del mundo de las formas geométricas, la República y los diálogos trabajados en equipo con los académicos y varios legisladores formados en la escuela para definir el perfil político académico, necesario para dirigir a la ciudad y gobernar a la ciudadanía.

La obra de su discípulo Aristóteles, fundador del Liceo, emprendió una labor pedagógica en Assos entre los años 347 y 345 a. C. Sin embargo, esta actividad no supuso el inicio de su escuela filosófica ya que se trataba de una extensión de la Academia de Platón, a la cual pertenecía. No será hasta que Jenócrates obtuvo el cargo de escolarca de la Academia (sucediendo a Espeusipo) en 339 a. C. cuando el Estagirita se dispuso a fundar su escuela.

En el Liceo también se trataban temas políticos, pero, por el riesgo de ser acusado de macedonismo, el Liceo no participó en la vida política. Respecto a la investigación histórico-política, en el Liceo se emprendió la tarea de compilar las 158 constituciones griegas. Las investigaciones naturales y analíticas también despuntaban en esta institución, con estudios de la clase del Organon y la Física de Aristóteles. En la última etapa de Teofrasto como escolarca prevaleció la tarea enciclopédica y con la influencia de Eudomo abundaron los trabajos en ética. 
La evolución de estas escuelas debe ser considerada desde los inicios de las reflexiones de los filósofos elementistas y sofistas, entre otros y sobre todo resaltar que en la Academia de Platón existieron grandes debates y diferencias de pensamiento, acto que puede ser ejemplificado como el surgimiento de la libertad de cátedra. Todos los avances logrados en las disciplinas investigadas por los filósofos, legisladores, religiosos y académicos se logran gracias a la agrupación y trabajo autónomo que maestros y discípulos consolidad y dan origen a los siguientes principios: la autonomía, la investigación y la libertad de cátedra, ejercidos en un espacio llamado Academia o Liceo y que dan origen a lo que hoy concebimos como Educación Superior.

\section{La escuela en los romanos}

La ciencia, el conocimiento y las instituciones avanzan, nunca se quedan estancadas, los quinientos primeros años de nuestra era dan paso al empoderamiento de los romanos, a la creación de ciudades del saber, como Alejandría y Constantinopla y así mismo sus emperadores instituyen al cristianismo como religión única y obligatoria en todo el imperio romano.

Justiniano fundador de las leyes para definir y garantizar la existencia de ciudadanía, consolida este proyecto apegado al pensamiento religioso del cristianismo y define a los filósofos de la escuela platónica como ideologías paganas.

El año 529 decide privar a los paganos de la facultad de enseñar y dispone la clausura definitiva de la escuela de Atenas la cual posee todavía un valor altamente simbólico de autonomía y libertad de reflexión. Justiniano promulgó un edicto dirigido a los atenienses, por el que se prohibía la enseñanza de la filosofía y de la jurisprudencia. Su clausura continúa representando el fin de la especulación filosófica pagana arruinada por la intolerancia religiosa del cesaropapismo bizantino. Esta interpretación ha influido de manera muy especial en los investigadores consagrados a la historia del pensamiento antiguo, la han utilizado para designar el término de la labor intelectual ligada a las antiguas creencias y han llegado a vincular, incluso cronológicamente, los acontecimientos atenienses de 529 con otros como la fundación de los Monasterios o la desaparición del consulado, con objeto de recalcar de un modo más preciso el tránsito de la edad antigua a los tiempos medievales. Y que para el propósito de este artículo nos es significativo para analizar los cambios que se dan al final del siglo XX en donde en Europa y América los países líderes de la economía, instituyen la globalización económica que tiene como principios centrales: la apertura de mercados, la cancelación de aranceles, entre otros y sujetar a la educación superior a las leyes de la oferta y la demanda, proyecto denominado neoliberalismo.

El hecho de referirnos a este suceso tiene el propósito de demostrar que la Constitución de Justiniano no es, sino una disposición más de las muchas dictadas por el poder imperial a lo largo de la antigüedad tardía con el fin de extirpar el paganismo y que, como la casi totalidad de ellas, obtuvo en su aplicación unos efectos prácticos muy limitados, es decir surge un nuevo modelo educativo; la educación patrística y monástica.

Los monasterios fueron los lugares donde se concentró todo el conocimiento de esta época en Europa, pertenecientes a la Iglesia cristiana, ya que Justiniano, pretendía unir al Imperio Romano en una sola fe, así pues, la educación patrística dominó el pensamiento. 
Se identifica a la educación patrística (desarrollada durante el siglo I al V d. C.) como el conjunto de escritos doctrinales de los primeros siglos del cristianismo. Tiene como objetivo unificar las diversas interpretaciones del cristianismo para dar sustento y lenguaje filosófico y adaptarse a las clases cultas de esa época.

Sin embargo, los primeros escritos cristianos y la formación de los predicadores tuvieron que convivir con otras tendencias religiosas y filosóficas por lo que tuvo que defenderse atacando a estas posturas, pero a su vez acoplando sus conceptos a sus ideas. Se hace presente el debate natural que existe en todo acto educativo; diferencias de pensamiento, interpretaciones ideológicas y filosóficas que deben existir en la construcción del conocimiento. Y es a través de la autonomía, la libertad de pensamiento; la manera que permite ser el camino para unificar ideas y saberes.

Ejemplo de esta obra es San Agustín (354-430) quien integró de manera exitosa en su obra los preceptos del cristianismo y las doctrinas filosóficas, como el judeoalejandrismo y el neoplatonismo. En su obra, San Agustín se dedicó a establecer argumentos que apoyaran la existencia de Dios, aunque no se esforzó demasiado en demostrarlo racionalmente. $\mathrm{Su}$ punto de partida era la fe, por lo tanto, no consideró dar pruebas de Dios en este sentido, lo importante era predicar la verdad divina, un camino para amar a Dios, de esta manera creó la base de toda la teología cristiana, ejemplo de un original trabajo de academia.

Durante el siglo VI se consolidan las escuelas presbiterales que se abocan a la formación de clérigos. Las guerras, los cambios sociales y culturales generar desconcierto y descrédito de la formación en estas escuelas. Y son motivo para que Carlomagno alrededor del siglo 781 d. C. proponga una transformación con la Escuela Palatina, con el solo propósito de devolverle al clero una dignidad fundada en la formación intelectual y un comportamiento moral, así como permitirían formar personas cultas que le ayudaran a administrar su imperio.

Los orígenes del movimiento filosófico medieval están ligados al esfuerzo de Carlomagno por mejorar el estado intelectual y moral de los pueblos que gobernaba y por hacer retroceder la barbarie introducida por las sucesivas olas de invasores. Para llevar a cabo esta tarea, el emperador Carlomagno se propuso restablecer las escuelas (las antiguas romanas habían desaparecido y las cristianas eran de una calidad ínfima) dotándolas de un programa de estudios que permitirían formar personas cultas que le ayudaran a administrar su imperio. Nace así la Escuela Palatina como lugar de encuentro de sabios y eruditos siglo VIII y IX (Le Goff. 1999) y (Pulido, 2018).

\section{Las escuelas monacales y surgimiento de las universidades}

En los monasterios y catedrales, encontramos desde su origen eclesiástico, las primeras escuelas que anteceden a las universidades sustentan muchas referencias anecdóticas de los monasterios como fundadores de todo el lenguaje universitario. La vida en el monasterio es el espacio de reflexión forjador de la esencia propia de Europa, que es el sustento para estructurar y desarrollar la universidad. No solo en el monasterio se organizan las primeras escuelas formadoras de los novicios, sino que la vida monástica configura los llamados, claustros universitarios.

Las universidades europeas tienen un origen en dos vertientes. La primer vertiente: las más antiguas surgieron como corporaciones que responden a la demanda de algunos jóvenes por 
adquirir los conocimientos específicos que se necesitan para el desempeño de algunas profesiones, por ejemplo, los estudios sobre Teología, en la Universidad de París; los estudios de derecho, canónico y civil en la Universidad de Bolonia ambos constituyen los primeros saberes a cuyo servicio nace la universidad.

La segunda vertiente se refiere a las fundaciones eclesiásticas, posteriormente civiles, señoriales, reales o imperiales, y que nacen con el fin de formar personal especializado que requiere la Iglesia como teólogos, canonistas, así como juristas y médicos, perfil que cumple desde sus inicios la universidad de París constituida en 1231. A la cual se le llamó universitas magistrorum parisiensis. Universitas significa corporación y alude primero a la de estudiantes, luego a la de profesores, para pasar a denominar la integrada por ambos cuerpos universitas magistrorum et scholarium, denominación que prepara el terreno para que desde finales del siglo XVI se fuese generalizando el término universidad para denominar a la institución en su conjunto, sustituyendo a la antigua denominación de studium litterarum, y si contaba con una bula papal, studium generale. Solo bastante más tarde el término de universidad, universitas litterarum, hace referencia a la universalidad del saber que la institución pretende transmitir (Moncada, 2007). La universidad de París fue la primera ya que se constituye bajo los principios que definen estructural y académicamente a una universidad, ya que estaba constituida a partir de las cuatro facultades clásicas: teología, derecho, medicina y artes liberales, además realizaba procesos administrativos de graduación y otorgamiento de títulos.

No existe fuente precisa de referencia sobre la fundación de la primera universidad del mundo, diferentes autores refieren a la universidad de Bolonia, al funcionar como Escuela de Derecho desde principios del siglo XI. Sin embargo, otra versión, afirma que fue la universidad de Paris.

La Iglesia cristiana sufrió momentos de crisis debido a la feudalización del clero, la venta de sacramentos, el tráfico de reliquias, desobediencia del clero, entre otros, revelando una corrupción desde dentro de la institución. Por lo tanto, el papa León IX realiza reformas, que después se le conocerían con el nombre de Reforma Gregoriana. Entre sus objetivos más importantes se encuentra el elevar el estatus del clero a través de una fuerte formación bíblica, es decir, de valores cristianos para reafirmar su respeto y autoridad, de esta forma serían preparados para luchar contra las herejías usando la retórica y la dialéctica. De este modo no solo era reeducar al clero sino también al pueblo, por lo que el papa impulsó la creación de monasterios y catedrales (Mora, 2008). Algunos Monasterios y abadías localizados por toda Europa (como Monte Casino en Italia, Saint-Martin de Tours o Saint Denis en Francia y Reichenau en Alemania) comenzaron a realizar acciones de preservación y mantenimiento de textos, copiándolos y traduciéndolos del griego y árabe al latín, además de ser focos de enseñanza y educación. Se consolidaron como centros de conocimiento ya que los manuscritos eran confinados en lugares especiales para su conservación, creando así las primeras bibliotecas medievales (Pulido, 2018; Tamayo de Serrano, 2007).

Las principales acciones de las escuelas monacales son reconocidas al constituirse en centros distantes de cultura con gran presencia educativa y cultural, operaban como escuela "interna" y a su vez se constituyeron en centros de enseñanza para estudiantes externos. Sin embargo; dichas escuelas monásticas, junto a todo el sistema de enseñanza, pasaron del éxito a la obsolescencia; crisis presente en el siglo XI y parte del XII, salvo excepciones 
pues las tendencias místicas y las reformas de búsqueda espiritual tendieron a olvidar e incluso desdeñar el estudio como herramienta de fortaleza moral y de sabiduría cristiana, fin principal de la educación. La recuperación en el siglo XII terminará por introducir cambios como, por ejemplo: cerrar la escuela "externa" a finales del siglo XII (Pulido, 2018).

En las ciudades más habitadas nacieron las escuelas urbanas, en su mayoría eclesiásticas y también existieron escuelas públicas o laicales, llamadas comunales. Estas escuelas fueron clave para la formación administrativa dado que durante este periodo imperial el ejército toma el control de las escuelas urbanas, provocando la cancelación de su autonomía. En este mismo periodo, las escuelas urbanas vinculadas a la catedral y al orden episcopal, tuvieron un gran impulso durante el siglo IX a instancias del gobierno carolingio, consideraban como prioritario formar un clero que tuviese a capacidad de cumplir su papel de liderazgo religioso y político que lograra unificar la cultura, que fuese capaz de comprender e interpretar los manuscritos y códices con veracidad (Pulido, 2018).

Analizando estos sucesos podemos referir que existe crecimiento y consolidación de las universidades, pero sujetas a los lineamientos del pensamiento e ideología del cristianismo, las instituciones vivieron este proceso de una forma compleja. Por una parte, crecieron gracias a que los monarcas decidieron pagar nuevas cátedras o contribuir en la construcción de nuevos edificios. También porque numerosos jóvenes querían estudiar para encontrar una colocación en la administración de los reinos. Pero, así como los reyes aumentaban sus aportaciones a las universidades y buscaban en ellas a sus cuadros dirigentes, también buscaban controlarlas, para que el dinero destinado se ejerciera correctamente y para que la formación de los jóvenes fuera útil al gobierno del reino. Es decir; las universidades sufrieron la intervención de los reyes como una lesión a la autonomía. Recibían dinero y nuevos alumnos, pero no eran libres de gastarlo como mejor decidieran ni sus enseñanzas podían ir en contra de los intereses de la realeza. Fue una época de crecimiento en infraestructura, pero con grandes limitaciones académicas, se matriculaban miles de alumnos, pero la enseñanza solamente privilegiaba la autoridad y desdeñaba la creatividad.

Las universidades tal como hoy se conocen provienen del occidente cristiano, la extensión de las escuelas medievales fueron el sustento de un emblemático propósito, el de profundizar en el saber para dar origen a tres actividades específicas: la investigación, la enseñanza (docencia) y la creación de teorías. La universidad fue una idea aportada por la edad media, donde sus debates y luchas entre el clero y los emperadores, por definir las labores propias de la enseñanza y el que debía enseñarse dieron origen a la autonomía que se extendió por toda Europa y más tarde por todo el mundo.

\section{Las universidades del siglo XIII al siglo XIX}

A comienzos del siglo XIII se establecieron las facultades, dando origen a la estructura propia de las universidades; las primeras fueron las de Artes y Tecnología; pronto nacieron la de Derecho, Filosofía y Medicina posteriormente, entre otras la de Matemáticas y Ciencias Naturales. Es necesario precisar que la universidad de Paris se puede considerar como la primera porque incluía en su estudio más de un área de conocimiento, por lo que, si bien anteriormente se estudiaba medicina en Salerno y derecho en Bolonia, una facultad no constituye una universidad. Sin embargo, lo que sí es una realidad es que la universidad de Paris en el siglo XIII fue el centro intelectual más importante de toda la cristiandad. 
Por otra parte, surge en Alemania la facultad de Medicina la cual pasó a constituir una categoría aparte de las demás, que representaban campos ligados a la Filosofía. Referencia, hasta nuestros días, de estas dos categorías de facultades son los dos tipos de grados doctorales, que, siguiendo el modelo alemán, otorgan las universidades norteamericanas y que universidades de Europa y América latina han seguido usando para el máximo grado académico que se otorga: el Philosophical Doctor (PhD), con sus diversas menciones, y el Medical Doctor (MD).

Con lo que respecta a la Facultad de Artes, debemos señalar que la palabra, artes, no se refiere a las creaciones artística, sino que designa el saber técnico encaminado a un fin práctico. Siendo a su vez el uso del antecedente en el desarrollo cultural de Occidente concepto que tiene su origen en la Grecia Clásica al cual se le denominó las Artes Liberales. Las cuales corresponden a la educación superior, reservada a quienes dirigían sus estudios hacia la ciencia suprema, la Filosofía, en la que debían formarse los futuros gobernantes. Las Artes Liberales consistían en estudios útiles destinados al hombre libre, no atado al ejercicio de un oficio fútil. Ninguna otra actividad debía ser parte de la formación académica si el único fin consistía en preparar un hombre para una profesión como medio de subsistencia. Pertenecían al programa de formación las siguientes áreas de estudio: leer y escribir correctamente, gimnasia, música y dibujo, aritmética, geometría y astronomía.

Áreas de estudio o materias que fueron perfilando las siete Artes Liberales: gramática, retórica y dialéctica, conformando el trivium, y aritmética, geometría, astronomía y teoría musical, que integran el quadrivium. Estos estudios liberales formaban el núcleo de lo que se enseñaba en la Facultad de Artes, materias que debía cursar todo alumno antes de ingresar a otras facultades. En ese paso se obtenían dos grados académicos: primero, el de Bachiller, y después, el de Magister. Las demás facultades otorgaban el grado de Doctor. La Licenciatura, instituida ya en el studium generale, no era un grado académico, sino la licencia para enseñar.

La universidad de la Edad Media, da inicios a lo que hoy definimos como estudios de carácter profesional Ortega y Gasset (1969, citado por Chuaqui, 2002) lo califica como, una universidad cultural: dedicada principalmente a la transmisión de la cultura de su época, esto es, de un sistema completo e integrado de las ideas substantivas del saber de entonces. Podemos afirmar que la crisis de la universidad medieval consiste precisamente en que su visión de síntesis cultural perdió vigencia cuando la sociedad se va transformando social y culturalmente y exige profesionales y científicos. Aquí surge la importancia de la investigación, como una actividad colegiada, ya que se realizaba como obra de personas aisladas y carecía de un cuerpo académico organizado para este fin.

Es hasta el inicio del siglo XIX el surgimiento de modelos de universidad: la que forma profesionales para el trabajo y la que se dedica a hacer ciencia. Los diferentes países de Europa y Norteamérica, incluyendo América Latina, adoptan en forma separada la misión de formar profesionales.

En la primera década del siglo XIX Napoleón forma la universidad profesionalizante nombrada la Universidad Imperial que surge después de cerrar las universidades denominadas tradicionales. Esta universidad fue una corporación estatal de carácter centralista, responsable de toda la enseñanza universitaria y escolar, su principio filosófico fue formar intelec- 
tuales con un saber práctico y útil a la sociedad, tuvo sedes en las provincias. Define a la función de enseñar como un privilegio del Estado y que su fin principal consiste en formar a los ciudadanos.

Las razones que explican la transformación de la universidad y un nuevo avance de la autonomía son muchas; siendo los factores socioeconómicos tan importantes como los ideológicos, pero lo cierto es que la reforma protestante tiene un fuerte sustento en la redefinir la autonomía universitaria y la libertad de cátedra. Martín Lutero (1483-1546) era un profesor de Teología sin renombre ni reconocimiento, el 31 de octubre de 1517, cumpliendo con un ritual universitario, cuelga las 95 tesis sobre las indulgencias en el pórtico de la iglesia universitaria de Todos los Santos de Wittenberg. Las respuestas de los teólogos, como la muy conocida del Dr. Johann Eck (1486-1543), profesor de la Universidad de Ingolstadt, encajan en el estilo universitario de la disputatio. ${ }^{2}$ Los reformadores son profesores universitarios, o por lo menos, personas que habían pasado por la universidad: Jan Hus (1372-1415) fue incluso rector de la Universidad de Praga en 1409; Felipe Melanchton (1497-1560), helenista de prestigio, autor de una grámatica griega, había helenizado hasta su apellido; Huldrych Zwingli (1484-1531), que había estudiado en las universidades de Viena (1498) y Basilea (1502-1504), recurre también a la disputatio para presentar sus famosos 67 artículos; en fin, Jean Calvin, (1509-1564), Calvino, discípulo del gran humanista Guillermo Budé y autor de un estudio sobre De clementia de Séneca, era un buen latinista y dominaba el griego. ${ }^{3}$

Las guerras de la religión que se surgen en los siglos XVI y XVII, afectaron a la universidad, también definen a su vez su larga decadencia. La ruptura de la unidad religiosa en la Europa occidental la universidad, debate su existencia entre la Iglesia y la Corona. En el mundo protestante, la desamortización de los bienes eclesiásticos perjudicó a la universidad, ya que le arrebató la autonomía económica, haciéndola depender en cada vez mayor medida del Estado. En las ciudades donde permanece el catolicismo, aumenta la vigilancia, sobre todo donde tiene presencia la Inquisición, empeñada en perseguir toda sospecha o indicio de herejía luterana, trastornan las funciones académicas y de investigación, con lo que desaparece de la universidad la actividad de innovación racionalizadora, añeja en una escolástica cada vez más rutinaria.

El surgimiento de las ciencias en los siglos XVII y XVIII ocurre fuera de las aulas universitarias. En todo caso, el hecho memorable, que constituye sin duda el mayor agravio de la universidad, es que la revolución científica se construye fuera, incluso en contra, de la universidad. La revolución humanista del Renacimiento había ocurrió fuera de las aulas universitarias ya que ésta dirigía sus actividades de docencia, exclusivamente, en preparar al personal profesional: teólogos, juristas y médicos que demandaba la sociedad, por tanto; el estudio de la cultura clásica y sus valores estéticos o humanistas quedó fuera de su proyecto educativo.

2 En el escolasticismo medieval, la disputatio fue, junto con la lectio, uno de los métodos que consiste principalmente en la contraposición de opiniones para llegar a la verdad, métodos esenciales y omnipresentes de enseñanza e investigación, así como una técnica de examen en las universidades desde principios del siglo XIII.

3 Los reformadores son profesores universitarios, o por lo menos, personas que habían pasado por la universidad: Jan Hus (1372-1415) fue incluso rector de la Universidad de Praga en 1409. 
Para el desarrollo de las ciencias se requiere autonomía y en las condiciones de la universidad medieval que preservan su origen confesional hace falta un espacio secularizado de tolerancia religiosa que excepcionalmente encontramos en algunos rincones de Europa: en los Países Bajos, tras su independencia de España; en Inglaterra, después de la "Revolución Gloriosa". Las ciencias nuevas surgen como una actividad privada, fuera de las instituciones oficiales. Los pioneros de las nuevas ciencias mantuvieron estrechas relaciones epistolares (escritura dirigida a una persona o grupo de personas), ya que por suerte las minorías cultivadas de entonces, como preciada herencia de la universidad medieval, disponían de una lengua común, el latín. En estas sociedades secularizadas, en las que se va consolidando la tolerancia religiosa, semilla de la libertad de cátedra y de las otras libertades en educación, los príncipes y monarcas reconocen las ventajas y el alto rendimiento que estos saberes tenían para el fortalecimiento de sus ejércitos, apoyaron la fundación de "academias" y "sociedades científicas".

Estas academias y sociedades científicas generan una renovación de la educación superior en conjunto, rumbo hacia la modernidad, Escocia, Prusia y Francia implementan reformas del Estado que su principal acción consiste en practicar la tolerancia religiosa, valor académico del que fueron fluyendo las demás libertades. Hugonotes, ${ }^{4}$ pietistas $^{5}$ y calvinistas encontraron en Prusia un espacio de libertad que promueve resultados muy pronto, especialmente para el desarrollo de las ciencias.

El reformista Federico III, fundador de la Universidad de Halle en 1694 en dónde confluyen el pietismo y calvinismo promueve las ciencias físico-naturales y considera que la fortaleza y el bienestar de un país se medirá por el vigor de sus universidades. En la interpretación de la ciencia, como índice del poder de una nación, se percibe la conexión que subyace entre nacionalismo y universidad vinculación que va a terminar siendo uno de los rasgos esenciales de la universidad alemana del siglo XIX y primeros decenios del XX.

Desde este planteamiento de servicio al Estado, la universidad alemana se define como la primera con fines de "servicio público" gira, en primer término, en torno al cultivo del Derecho y todos los demás saberes administrativos que necesita el funcionario. En Halle se crea en 1727 la primera cátedra que se ocupa de "las ciencias cameralistas, económicas y policiales", que hoy traduciríamos como una cátedra dedicada a la economía, el derecho administrativo y la administración pública. También presta particular atención a las nuevas ciencias naturales, consideradas fundamento del desarrollo económico y social. A comienzos del XVIII, ya se percibe en Prusia la conexión existente entre desarrollo de las ciencias y progreso económico y social.

La universidad alemana ejemplifica el nuevo sentido de la autonomía: responder exclusivamente a las necesidades y planteamientos que impone el hacer científico, haciendo abstracción, como si fuera posible e incluso deseable, del medio en el que se desenvuelve. Con ello

4 Este vocabulario (en antigüedades) se define a una persona seguidor, adepto, simpatizante o fanático de la doctrina o herejía calvinista instaurado en Francia, instaurado por el teólogo francés Juan Calvino en que fue excomulgado por la iglesia, también como movimiento político y religioso a medianos del mediados del siglo XVI, perteneciente o relativo a los integrantes de esta secta.

5 Pietismo es el término que denota un movimiento en favor de la religión práctica dentro de la Iglesia luterana de los siglos XVII y XVIII. Fundado en Halle por Philipp Jakob Spener y siguiendo distintos cursos individuales de desarrollo en Halle, Württemberg y Herrnhut recibió un lazo de unión en su convicción de que el tipo de cristianismo entonces prevaleciente en el luteranismo estaba urgentemente necesitado de reforma, la cual podía ser estimulada por la "piedad", fe viva hecha activa y manifestada en una conducta recta. Doctrina religiosa protestante que tuvo su origen en las ideas el pastor J. Spener (1635-1705); se caracterizó por oponer a la frialdad derivada de la idea de la justificación por la fe, una religión del corazón, un sentimiento más sincero y emocional. 
queda de manifiesto que el prototipo de esta universidad nueva es la academia, institución ilustrada por excelencia, creada con el fin exclusivo de incrementar el saber científico. La universidad berlinesa toma como arquetipo a la academia y, como tal, se concibe como una "comunidad de maestros y discípulos, dedicados por completo a la búsqueda de la verdad". Considerando como objetivo básico de la universidad preparar a los profesionales que requiere la sociedad, el nuevo modelo alemán apunta a otro propósito: formar los científicos que pide el desarrollo de la ciencia.

La Universidad de Humboldt consolida la función de la investigación científica y trabaja en la incorporación de los nuevos conocimientos en la enseñanza. La reforma impulsa el desarrollo de todas las ciencias. El grado académico de Doctor se instituye tal como lo concebimos en la actualidad: un grado que acredita la capacidad como investigador independiente.

Se integran la docencia con la labor del investigador y se define como labor del docente la de comunicar los nuevos conocimientos y no limitarse a lo escrito en los libros. Se innova el trabajo de la docencia: se promueve que el profesor no vea a la universidad como un lugar de paso, se considera como importante que se dedique por completo a la labor académica.

Humboldt creó una universidad basada en un renovado concepto de la ciencia y la autonomía. La gran renovación de las universidades se desarrolló en Berlín. Teniendo como principal premisa: que la ciencia está en continuo e ilimitado crecimiento, que los docentes no poseen conocimientos definitivos, sino que aprenden con la investigación y que solo tienen un poco más de experiencia que los estudiantes. El aula con su modelo didáctico tradicional de lecciones magistrales dio paso al seminario y al laboratorio, donde la inteligencia y la creatividad son las directrices que definen la autoridad del docente.

La nueva metodología didáctica para tener éxito necesita de absoluta libertad de trabajo y de pensamiento, pero también es necesario las condiciones materiales para que docentes y estudiantes pudieran dedicarse de tiempo completo al estudio. Así, el Estado debía garantizar a las universidades plena autonomía académica y un total apoyo económico.

\section{Inicio de las universidades en América Latina y El Caribe}

Las primeras universidades creadas en el Nuevo Mundo, la Nueva España o América (Nombres acuñados por los diferentes países de Europa, hasta antes de los movimientos de independencia) se ordenan en Santo Domingo en 1538, posteriormente en 1551 se crean las universidades de San Marcos en Lima y la Real Universidad de México (González, 1987), existe un dato importante de considerar: primero surge la universidad antes que las escuelas de educación básica. América Latina contaba con 13 Universidades, cuando Harvard fue fundada (1636).

Entre España y Portugal como potencias coloniales europeas, con respecto a la fundación de universidades en las tierras colonizadas se considera una verdadera excepción por parte de la corona española. Portugal, por el contrario, consideró a la obligación de estudiar en la metrópoli, impuesta a quienes quisieran acceder a la universidad y hubieran nacido en las colonias, como un sustento de la dependencia de estas últimas (Steger, 1974, pp. 103104, 156). 
El número formal de universidades instauradas fueron más de 30, muchas no trascendieron de lo nominal, solo se puede reconocer el nivel como universidad a unas pocas que incluyen las de México, Lima, Córdoba y Santiago de Chile. Las universidades fueron creadas junto con el poder real y con la cruz. Algunas autorizadas por el Papa, como las de Santo Domingo, Bogotá y Quito; otras por el Rey, como en los casos de las Universidades de México, Lima y Santiago de la Paz (Santo Domingo). La universidad del Nuevo Mundo quedó adjudicada desde su propia instalación en el Nuevo Mundo a los poderes eclesiástico y real. Debemos señalar su diferencia con las viejas universidades europeas, que nacieron de la voluntad de esos poderes antes que desarrollarse contra ellos, como ocurrió en París, Oxford o Bolonia. Por el contrario, en el Nuevo Mundo, las universidades son importadas y su establecimiento es otorgado desde arriba y desde fuera, por un acto administrativo" (Brunner, 1992).

La primera de todas, en Santo Domingo, respondió al modelo de "convento-universidad" de Alcalá, universidad centralmente preocupada por la teología, cuyo rector era también el prior del convento, y con mayor independencia del poder civil. Salamanca en cambio, la primera universidad de España, se vinculó en sus orígenes con la idea de servicio a la nación, o más bien a la monarquía. "Las dos fundaciones universitarias más importantes del período colonial, Lima y México, ambas de 1551, fueron creadas por iniciativa de la corona y tuvieron el carácter de universidades mayores, reales y pontificias. Su influencia en las restantes universidades del Nuevo Mundo fue decisiva. Sus constituciones y estatutos, inspirados en la tradición salamantina hasta en los menores detalles, fueron adoptados o copiados por muchas otras universidades de América Latina (Ibídem, p. 17-18).

En el siglo XIII las universidades en tierras españolas se caracterizaban por su estrecha relación con las monarquías de sus respectivos territorios: de acuerdo a la posición que Alfonso el Sabio asignó a Salamanca, cada una disponía del monopolio docente en un territorio determinado y estaban bajo la directa autoridad real. Pudiendo definirse como universidades estatales (Steger, 1974, p. 160). El "modelo salamantino" condujo a tres de las seis universidades hispanoamericanas fundadas en el siglo XVI, las de México, Lima y Santiago de la Paz, esta última la segunda establecida en tierras dominicanas, y en oposición a la ya existente. Como ya se observó, las otras tres universidades -las de Santo Tomás de Aquino en Santo Domingo, Bogotá y Quito- respondían al modelo de Alcalá; enfoque consolidado, tanto en España como en América a partir de la gestación de la Contrarreforma, sobrepasando la influencia original de los esquemas culturales de Salamanca, universidad que tuvo un espíritu más abierto, sensibles a aceptar las enseñanzas de Copérnico. Factor que influye para la inclinación humanista que caracterizó los primeros tiempos de la Universidad de México. Pero ello no duró: más allá de las diferencias de origen y de estructura de los diversos establecimientos, la importación de la universidad a la América Hispana tiene lugar en el clima espiritual de la Contrarreforma; la institución debe formar los nuevos grupos dirigentes y ser un puntal de la "conquista espiritual” (Steger, 1974, pp. 163-164). Propósito que se ilustra elocuentemente con el impulso fundacional de los jesuitas, que en el breve lapso que va de 1622 a 1625 establecieron seis universidades en América del Sur (Ibídem, p. 182). 
Impresindible mencionar la fundación en marzo de 1624 de la Universidad de San Francisco Xavier, con los títulos de Universidad Mayor, Real y Pontificia a través de la Bula Papal emitida por Gregorio XV el 8 de agosto de 1623 y el Documento Real emitido por el Rey Felipe III el 2 de febrero de 1622. El sacerdote jesuita Juan Frías de Herrán responsable de la fundación de la Universidad, su primera autoridad académica el sacerdote Ignacio de Arbieto. Las primeras materias que se dictaron fueron Teología Escolástica, Teología Moral, Filosofía, Latin y el lenguaje nativo aimara. Posteriormente en 1681 se incluyó el Derecho canónico.

\section{Autonomía y reflexiones de las universidades de América Latina y El Caribe en el siglo $X X$}

Podemos definir que entre los años 1918 y 1929 fueron escenario de la reforma universitaria en América Latina, sus principales protagonistas los estudiantes, las formas de lucha estudiantiles fueron parecidas en todos países con resultados diferentes. La Universidad Mayor de San Carlos y Montserrat de Córdoba, Argentina en 1918 fue el lugar de origen del movimiento de reforma y proyectó su influencia a las universidades de toda América Latina, trasciende los límites de las aulas universitarias en los movimientos estudiantiles de San Marcos en Perú y en la Universidad de la Habana, Cuba hasta culminar con la concesión de la autonomía universitaria en México en 1929. El estudio y análisis de estos sucesos definen la configuración de la universidad latinoamericana, con absoluta independencia y diferencia de las universidades del resto del mundo. La clase política en la sociedad latinoamericana, anticlericales y nacionalistas, intentaban terminar con el poder de las oligarquías para transitar hacia la modernización de la sociedad. "La incipiente penetración del imperialismo norteamericano en la mayoría de los países de la región permitía reflexiones para vislumbrar el nuevo despertar del nacionalismo latinoamericano" (Rodó, 1975). Los universitarios habían resentido La sociedad en conjunto percibe las influencias de la Primera Guerra Mundial, la Revolución Mexicana y la Revolución Rusa. La Primera Guerra Mundial destruyó la imagen de una Europa prospera y pacífica, cuyo desarrollo económico lograría el bienestar de las mayorías. Las revoluciones mexicana y rusa se ejemplifican como alternativas para los países en desarrollo. La dimensión latinoamericana y las experiencias de la revolución, así como las proezas de los líderes estudiantiles, cimentaron una coherencia no conocida en la historia. "Los líderes estudiantiles no propusieron categorías de estados nacionales, sino conceptualizaron a las universidades como pilares de la nueva América Latina" (Portantiero, 1978, y Cúneo, 2013). El Manifiesto Liminar, documento clave de la reforma de Córdoba, se dirigió a los "hombres libres de Sudamérica" y decía:

Córdoba se redime. Desde hoy contamos para el país una vergüenza menos y una libertad más. Los dolores que quedan son las libertades que faltan. Creemos no equivocarnos, las resonancias del corazón nos lo advierten: estamos pisando sobre una revolución, estamos viviendo una hora americana (Portantiero, 1978, p. 131; Roig, 1981; Funes y Caldelari, 2001).

La reforma universitaria en Córdoba en 1918 visualiza la autonomía universitaria como el enfrentamiento contra la sociedad oligárquica buscando el apoyo del gobierno representante de las clases medias. Resultando una situación contradictoria; por un lado, se referían a la experiencia histórica del desarrollo de las universidades y legitimaron su propuesta de una 
autonomía de la siguiente manera: el Estado debía limitar su intervención en la universidad al otorgamiento del presupuesto y a la lucha en contra de influencias clericales en la vida universitaria. Por otro parte, nunca dudaron en incluir al gobierno para imponer sus fines: la rebelión estudiantil en Córdoba logra su victoria con la intervención gubernamental. El presidente Hipólito Irigoyen asumió una posición conciliadora con respecto a los asuntos universitarios y aprueba las demandas estudiantiles. Para el caso de México el movimiento estudiantil de 1929 no está en la agenda la autonomía universitaria como punto central de sus demandas, surge como punto adicional del pliego petitorio refiriéndose a la autodeterminación de la universidad; sin embargo, esta era una idea presente desde el proyecto de ley para la Universidad Nacional de México que presentó Justo Sierra en 1880 al Congreso de la Unión, reconsiderado en la misma Ley Orgánica de 1910 hasta el movimiento estudiantil de 1929.

Para el caso de Bolivia la Universidad de San Francisco Xavier de Chuquisaca fue la primera del país en alcanzar el carácter de Universidad Autónoma en el año 1930, tras arduas disputas con la Junta Militar y los gobiernos en turno. Esta universidad es líder de los movimientos en pro de la democracia en Bolivia ante las trasnacionales de la época y la defensa de los recursos y luchar por la consolidación de la autonomía junto con otras cinco universidades más: La Paz, Cochabamba, Santa Cruz, Potosí y Oruro, estas seis universidades vivieron el abandono que vivió el pueblo boliviano. El régimen autónomo, para ellas existía solo como un precepto constitucional, sin posibilidades de desarrollo concreto; pero que se consolida a través de un referéndum nacional, acto democrático en el que el pueblo mayoritariamente apoya la ansiada Autonomía Universitaria y que se inscribe en la Constitución del año 1931. Y se ejerce en las guerras del Chaco en 1932 (Miranda Pacheco, 1979).

Finalmente, el movimiento estudiantil de Córdoba define la autonomía en estrecha relación con la dirección democrática de las universidades que incorpora la participación de los estudiantes en las decisiones universitarias. Se estructura de la siguiente manera: el cogobierno de docentes, estudiantes y graduados, a fin de participar en el gobierno universitario y asegurar la transformación pedagógica, profesional y científica, en un ámbito de libertad de cátedra y de investigación, con el propósito de extender la cultura, democratizar la educación y adjudicar a la universidad la misión de alcanzar el bienestar social. Los componentes fundamentales de la autonomía son: "democratización del gobierno universitario, la libertad de cátedra, la crítica y la responsabilidad social, considerados como principios consustanciales del quehacer universitario" (Villarreal, 1999).

Las nuevas clases medias producto de las inmigraciones masivas a finales del siglo XIX, la economía de exportación de productos primarios que engendró rápidamente un mercado interno de manufacturas y un proceso de industrialización, tuvo su reflejo en las universidades latinoamericanas estaban lejos de responder a lo que los países necesitaban para un desarrollo propio y para hacer frente a la nueva problemática planteada por los cambios en la estructura social. Gran parte de este proyecto entró a los nuevos estatutos de las universidades aprobados por el gobierno y los estudiantes lograron así que se incorporaran muchas de sus demandas a una amplia reforma universitaria, formada por los siguientes acuerdos:

1. Elección, por la propia comunidad universitaria, de los cuerpos directivos de la universidad y participación de sus elementos constitutivos: profesores, graduados y estudiantes. 
2. Implantar concursos de oposición para la selección del profesorado y periodicidad de las cátedras.

3. Docencia libre.

4. Asistencia libre.

5. Modernización de los métodos de enseñanza.

6. Asistencia social a los estudiantes y con ello una democratización del ingreso a la universidad.

La experiencia del movimiento estudiantil de la Universidad de Córdoba fue el ideal que provocó la expansión de la educación superior, que se potencializa aproximadamente hacia 1960 y que llega hasta nuestros días, factor visible en todo el mundo. Su generalidad demuestra concluyentemente que no está impulsada por tipologías nacionales particulares, como las exigencias o los recursos económicos. La expansión de la educación superior forma parte, claramente, de un modelo global de sociedad y de educación. Modelo que adquiere poder a escala mundial, no porque las sociedades del mundo sean similares, sino porque sus objetivos se centran, de modo homogéneo, en el desarrollo socioeconómico y porque, en todas las ideologías dominantes del mundo, se considera que la educación es el principal instrumento para alcanzar desarrollo sostenible.

\section{Neoliberalismo y las universidades de América Latina finales del siglo XX}

Durante la década de los 90 se empodera el movimiento neoliberal y realiza un ataque conceptual y estructural hacia la educación superior en América Latina. Desde entonces, los neoliberales adoptaron como eje de su reflexión y crítica el papel del Estado como regulador de la economía. Su propuesta consistió en voltear el modelo keynesiano, que en Estados Unidos tuvo durante muchas décadas como paradigma al New Deal Rooseveltiano (Nuevo Trato de la política intervencionista de Estados Unidos). En gran Bretaña las tesis neoliberales se fusionaron con el neoconservadurismo y produjeron la mezcla explosiva del thatcherismo. Muchos neoliberales abandonaron las tesis monetaristas, que desde los setentas tuvieron como firme defensor a Milton Friedman. La propuesta monetarista era clara: el origen de la inflación está en el gasto público excesivo. A este había que reorientarlo, reduciendo el papel económico del Estado a su mínima expresión, para promover a cambio la libre empresa.

Indudablemente la fusión entre neoliberales y neoconservadores tuvo un triunfo pírico al derrotar en el terreno económico a los gobiernos del socialismo autoritario del bloque soviético. El derrumbe del muro de Berlín, la desaparición de la Unión Soviética y la virtual muerte de los partidos comunistas que gobernador a los países detrás de la cortina de hierro constituyeron un indudable triunfo ideológico propagandístico de la coalición neoliberal-neoconservadora occidental.

Sin embargo, después de este triunfo la coalición no tuvo respuestas para los retos del llamado "nuevo desorden mundial". El belicismo ya no funciona ni en términos de racionalidad política ni mucho menos económica. Fenómenos como el acelerado deterioro ecológico mundial no encuentran respuestas en las clásicas fórmulas librecambistas ni en la 
promoción del modelo económico altamente concentrador y depredador. Por si fuera poco, la socialdemocracia europea también enfrenta una severa crisis de identidad que impide erigirla como modelo alternativo. Además, en términos de proyecto económico, no existieron muchas diferencias entre los programas reprivatizadores de España o Francia. Neoliberales y monetarista sin ser necesariamente lo mismo, los promotores de la ideología neoliberal y los llamados chicago boys, o monetaristas, ideólogos del modelo económico impulsado a través de instituciones internacionales como el Fondo Monetario Internacional o el Banco Mundial, se fusionaron a tal grado que suele referirse a ellos como si fueran sinónimos.

En esencia, ambos coinciden en la necesidad de reducir el gasto público orientado a los servicios sociales, impulsar la iniciativa privada, apoyar el libre comercio, disminuir la carga impositiva en forma selectiva. En términos económicos, los monetaristas se orientaron ante todo a la eficiencia del aparato productivo, sustituyeron el crecimiento como valor central frente a conceptos como desarrollo o bienestar social, y han sido incisivos y hasta obsesivos en el dogma del control inflacionario.

Uno de los especialistas del Banco Mundial que inició la crítica de la educación superior, fue el economista George Psacharopoulos (1995), quien en varios artículos señaló que los recursos dedicados a la educación superior no se utilizaban con eficiencia, por lo que la inversión en educación debía priorizar el nivel de educación primaria, cuya tasa de retorno social era mayor que el correspondiente al nivel superior. Como consecuencia, la política en educación superior debería encaminarse a la recuperación de costos, mediante la supresión de la gratuidad, el establecimiento del crédito educativo y un mayor apoyo a la educación superior privada (Ibídem).

Durante los análisis que realizan los organismos internacionales, destaca: "Documentos para discusión del Banco Mundial", apareció un extenso estudio elaborado por el economista Donald (1994), de la División de Recursos Humanos del Banco Mundial:

La asignación de recursos en las universidades públicas en América Latina es con frecuencia, ineficiente. Los salarios de los profesores son demasiado bajos para atraer a académicos a dedicarse de tiempo completo a la enseñanza e investigación y usualmente, el plantel facultativo carece del material y equipo necesarios para llevar a cabo su trabajo. Al mismo tiempo, el presupuesto administrativo y el personal administrativo de apoyo son excesivos. Una mejora en la eficiencia interna requerirá la introducción de modernos sistemas, información gerencial a los flujos de estudiantes y recursos, así como la introducción de criterios de desempeño en la asignación de recursos para la educación superior.

Las restricciones del presupuesto gubernamental para la educación superior abogan por una mayor eficiencia en el uso de este presupuesto. Se hace cada vez más necesario que los gobiernos consideren políticas de concesión de préstamos a estudiantes necesitados que asistan a universidades privadas, o que aseguren que las universidades privadas tengan acceso a mercados de capital para financiar las inversiones que requieran para su expansión. Se puede aumentar la recuperación de costos de las instituciones públicas eliminando los subsidios a servicios que no estén relacionados con la instrucción, y elevando los derechos de matrícula; al mismo tiempo que se introducen programas de préstamos y becas que mejoren el acceso de estudiantes de menores ingresos. El proceso presupuestario de la educación superior pública puede alterarse para incluir incentivos de desempeño que promuevan mejoras en la eficiencia interna. 
A partir de lo que denomina "las lecciones derivadas de la experiencia" sobre cómo lograr más eficiencia, calidad y equidad en la educación superior, el documento propone una estrategia de reforma, cuyas directivas claves serían las siguientes:

- Estimular una mayor diversificación de las instituciones públicas de educación superior e incluir el desarrollo de instituciones privadas.

- Proporcionar incentivos a las instituciones públicas, a fin de que diversifiquen sus fuentes de financiamiento, incluyendo el cobro de aranceles a los estudiantes y la vinculación del financiamiento del Estado a la mejora del rendimiento académico e institucional.

- Redefinir el rol del gobierno en la educación superior.

- Introducir políticas explícitamente diseñadas a dar prioridad al mejoramiento de la calidad y el fomento de la equidad.

En lo que respecta a la redefinición del papel del gobierno en la educación superior, el Banco aboga por una mayor intervención del gobierno central "en orden de asegurar un uso más eficiente de los recursos públicos". No se trata, aclara el documento, de un control directo, sino de utilizar el expediente del financiamiento público para estimular a las instituciones, públicas y privadas, a satisfacer más adecuadamente las necesidades de adiestramiento e investigación. La experiencia demuestra que la implementación exitosa de los procesos de reforma de la educación superior depende de:

a) la existencia de políticas nacionales coherentes que ofrezcan un marco general de referencia;

b) el establecimiento de incentivos e instrumentos, orientados por los principios de la economía de mercado, para implementar las políticas, y

c) mayor autonomía de gestión para las instituciones públicas. ${ }^{6}$

Los objetivos prioritarios para la reforma de la educación superior, según el Banco Mundial, deberían ser: $i$ ) incrementar la calidad de la enseñanza y la investigación; $i i$ ) mejorar la respuesta de la educación superior a las demandas del mercado laboral y a las cambiantes demandas económicas; e iii ) incrementar la equidad.

Las recomendaciones señaladas por el documento del Banco Mundial intensifican en América Latina a mediados de la década de los noventa una agenda de política pública activa en educación superior que demanda de las universidades objetivos tan variados como el incremento en las publicaciones científicas, una mayor eficiencia en la educación, la admisión de alumnos provenientes de sectores desaventajados, una colaboración más estrecha con el sector productivo, ente otros. Así mismo, aparece como requisito obligatorio el criterio de evaluación externa y de autoevaluación de las universidades que demuestren su eficiencia en la gestión apegado a procedimientos de acreditación o de nuevas formas de asignar el financiamiento por medio de instrumentos competitivos o asociados a resultados medibles.

En la medida en que los gobiernos universitarios exitosos son los que aprenden a sacar partido del nuevo ambiente, ganan terreno la legitimidad administrativa y corporativa que 
subrayan esa aptitud de innovar los nuevos esquemas de la educación superior, sin perder de vista que el objetivo final de esta gestión es incrementar y mejorar la producción de conocimiento y su diseminación.

El reduccionismo economicista de los planteamientos del documento del Banco Mundial sobre la educación superior y sus conclusiones sobre la tasa de retorno, suscita serias objeciones teórico-filosóficas, según José Luis Coraggio (1995), cuando se pretende dar tal centralidad al análisis económico en el diseño de políticas y procesos educativos. Dichas objeciones pueden resumirse de la siguiente manera:

a) Por análisis económico se entiende un método especial de análisis, encuadrado en la teoría económica neoclásica, la que por décadas ha sido objeto de críticas por sus limitaciones para explicar incluso los procesos específicamente económicos.

b) El modo economicista en que se usa esa teoría para derivar recomendaciones contribuye a introyectar e institucionalizar los valores del mercado capitalista en la esfera de la cultura, algo que va más allá de hacer un cálculo económico para comparar los costos y beneficios de diversas alternativas generadas desde lo social o lo político.

c) Se indica que dicho análisis es solo un punto de partida, sin embargo: los gobiernos tienen otros motivos para establecer sus prioridades educativas, de hecho, por razones que debemos determinar, las recomendaciones específicas y generales que vienen planteándose en los documentos del Banco Mundial parecen estar siendo asumidas acríticamente por muchos gobiernos de la región y del mundo.

d) Las nuevas políticas sociales propuestas, y las de educación en particular, no solo no son económicamente sustentables y conducen a nuevas crisis fiscales, sino que son ineficientes para los mismos criterios neoclásicos.

e) A pesar del enfoque cientificista en que vienen envueltas las propuestas oficiales del Banco Mundial, no se asume el principio científico de que están basadas en hipótesis sujetas a la refutación; por el contrario, parece haber más afán en seguir construyendo ejemplos que las hagan plausibles que en atender a las evidencias que las refutan.

f) En una época de crisis de paradigmas y de grandes incertidumbres, la gravedad de las consecuencias que puede tener una intervención masiva equivocada en el área educativa debería evitar el unilateralismo disciplinario y propender a la creación de un espacio pluralista de búsqueda colectiva, donde diversos criterios y propuestas plausibles sean investigadas y puestas a prueba con igual acceso a recursos.

Para encuadrar la realidad educativa en su modelo económico, y poder así aplicarle sus teoremas generales, el Banco ha hecho una identificación (que es más que una analogía) entre sistema educativo y sistema de mercado, entre escuela y empresa, entre padre de familia y demandante de servicios, entre relaciones pedagógicas y relaciones de insumo-producto, entre aprendizaje y producto, haciendo abstracción de aspectos esenciales propios de la realidad educativa... Como consecuencia, no debe extrañar que su propuesta básica para el sistema educativo consista en (hasta donde sea posible) dejar librada la actividad educativa al mercado y a la competencia, de modo que sea la interacción de demandantes y oferentes de servicios educativos la que defina cuánta educación, con qué contenidos y pedagogías, 
estructurada de qué maneras, en qué ramas y a qué precios debe ofrecerse... El problema, que tarde o temprano tendrán que asumir los intelectuales y técnicos del Banco, pero que ahora enfrentan nuestras sociedades ante las nuevas políticas educativas, es que nuestra realidad histórica (y más aún en el caso de algunas sociedades en otras regiones del mundo) no se ajusta al modelo, y que aceptar las propuestas a libro cerrado puede equivaler a aceptar una intervención política externa, o la introyección de valores no planteada abiertamente como opción a la sociedad (Tünnermann Bernheim, 2003).

Política externa que viola la histórica autonomía de las universidades, el ejercicio de la libertad de cátedra y principalmente limita el ejercicio sustantivo de la investigación. La hegemonía estadounidense que amenazaba con un mundo unipolar una vez caído el Muro, ha tenido que ceder y compartir con la Unión Europea buena parte de las decisiones que mueven la política y los mercados internacionales.

Sin embargo, hoy podemos observar que los estudios disponibles de los países desarrollados indican que, por sí sola, la educación no resuelve la pobreza. No nos referimos aquí a que también hay que invertir en capital físico y tener un marco macroeconómico abierto y estable (algo que sí sostiene el Banco). Nos referimos a que la inversión en educación solamente contribuye a reducir la pobreza en un contexto de crecimiento con políticas redistributivas del ingreso, mientras que, incluso con crecimiento, en el contexto de políticas y efectos redistributivos negativos, la educación no reduce la pobreza, ni siquiera en los países industrializados (Haddad, 1990). Por lo tanto, una política educativa eficiente no puede ser sectorial, sino que debe integrar, como condiciones de su eficacia, cambios en la distribución del ingreso y la riqueza, que en América Latina muestra una de las estructuras más regresivas del mundo. Sin embargo, si tomamos en conjunto las políticas educativas, sociales y económicas, esa lección no parece haber sido aprendida, actualmente las universidades latinoamericanas están sufriendo un nuevo recorte de su financiamiento y aportaciones del Estado.

Evidentemente, un mundo en el que la equidad y la inclusión logra que la mayoría de la población tiene acceso a la educación superior, incluso en la periferia más alejada, y a la educación en una ciudadanía mundial común, es un mundo transformado. Se deben intensificar enormemente los potenciales para la acción colectiva organizada. Un movimiento mundial arrollador en favor del medio ambiente se puede basar en la ciencia universitaria. Otro movimiento similar favorable a la reforma organizativa, la estandarización y la transparencia puede basarse en la ciencia social universitaria racionalista. Y un movimiento global sobre los derechos humanos puede celebrar los derechos y las capacidades de poblaciones altamente escolarizadas. Proyecto descrito en la Declaración Mundial sobre la Educación Superior en el Siglo XXI: Visión y Acción 9 de octubre de 1998, aprobado por los Estados miembros de la Unesco en la Conferencia Mundial sobre la Educación; y que hace contrapeso a la propuesta impulsada por el Banco Mundial y el Fondo Monetario Internacional.

La Conferencia Mundial sobre la Educación Superior aspiraría a identificar algunos principios fundamentales que, a escala mundial, pudieran servir de base para promover profundas reformas de los sistemas de educación superior y subrayar su contribución a la construcción de una cultura de paz, basada en un desarrollo con equidad, justicia, respeto a los derechos 
humanos, solidaridad y democracia, todo lo cual se logra con instituciones de educación superior dotadas de autonomía responsable y libertad académica que se ejerce en la cátedra y la investigación.

Durante los años de 1998 y 1999 se realizaron diferentes conferencias y trabajos para difundir la propuesta de la Unesco, no se lograron avances significativos, los gobiernos de los diferentes países de América Latina optaron por la postura de sistema educativo sinonimia sistema de mercado. Esta imposición en las políticas de la educación superior se ha visto además marcada por factores como: la incapacidad de los estados para financiar el crecimiento de la matricula; el aumento de la educación superior privada y la emergencia de nuevos proveedores mayoritariamente con ánimo de lucro; la diversificación de las fuentes de ingreso y los mecanismos de distribución de costes; la internacionalización y la provisión transfronteriza; y la importancia de la acreditación para la garantía de la calidad y de los rankings. Temas que fueron debatidos en la Conferencia Mundial de Educación Superior en París en julio de 2009 a diez años de la propuesta inicial realizada en la Conferencia General de la Unesco en 1999. La idea de bien público en la educación superior está directamente relacionada con los roles que las Instituciones de Educación Superior desempeñan en la sociedad. La Conferencia ofreció una plataforma global para el debate y el análisis con visión de futuro de la educación superior y la investigación, y alcanzó acuerdos sobre recomendaciones orientadas a la acción que permitirán que la enseñanza superior y la investigación respondan mejor a las nuevas dinámicas que formarán la agenda para el desarrollo de las políticas e instituciones de educación superior. La Conferencia ratificó la importancia de la educación superior y la investigación para hacer frente a los desafíos mundiales y construir economías basadas en el conocimiento que sean más integrador, equitativas y sostenibles.

Sin embargo, en la Conferencia de 2009 y nuevamente en el Foro Mundial de la Educación, en donde se plantea la agenda 2015-2030 a través de 17 Objetivos de Desarrollo Sostenible se siguen reiterando las mismas cosas, los mismos conceptos, no se avanza y, sobre todo, no se toman medidas. De veinte años a la fecha, las reflexiones no se ven acompañadas, como lo muestran algunos participantes, con acciones concretas de la Unesco. Por eso, uno de los temas de reflexión sobre la autonomía universitaria y que queremos que se impulse desde la región de América Latina y el Caribe, es que se adopten normas, acciones de gobierno y recomendaciones muy fuertes alrededor de la Responsabilidad Social, la Pertinencia, la Equidad, la Justicia, la Democracia y se construya una nueva cooperación internacional que busque equilibrio entre las regiones para evitar las grandes brechas que todavía padecemos.

La crisis civilizatoria actual implica la construcción de nuevos paradigmas con el fin de transitar hacia una sociedad mundial sostenible. Este proceso deberá ser liderado por la educación superior. Una de las tareas prioritarias para las instituciones de educación superior es poner a disposición el conocimiento existente y generar conocimiento nuevo al servicio de la construcción social.

Todos los sistemas de educación superior y las instituciones deberían dar prioridad a garantizar la calidad de los programas, la enseñanza y los resultados. Las estructuras, los procedimientos y los criterios estándar para garantizar la calidad deberían desarrollarse en el ámbito regional y nacional con arreglo a las pautas de actuación internacionales, a la vez 
que respeten la variedad en función de las características específicas de cada país, institución o programa. Además, las instituciones de educación superior necesitan los recursos económicos y humanos adecuados para aumentar la calidad de la educación.

La calidad de la educación superior es un concepto multidimensional que debería comprender todas sus funciones y actividades: la enseñanza y los programas académicos, la investigación y los estudios, la contratación de personal, los alumnos, los edificios, las instalaciones, los equipamientos, los servicios a la comunidad y el entorno académico. La autoevaluación interna y la revisión externa, realizadas abiertamente por especialistas externos, si es posible con experiencia internacional, son vitales para mejorar la calidad. La dimensión internacional de la calidad, la selección del personal y su formación continua, y la obtención de experiencia en las Tecnologías de la Digitalización de los procesos de enseñanza aprendizaje, los cuales también se consideran aspectos clave para la evaluación de la calidad.

Por tanto, la educación superior tiene una responsabilidad pública fundamental respecto a los contenidos curriculares, la ética y los valores que transmite. La reflexión sobre la contribución y responsabilidad social de las universidades implica una revisión a fondo de su misión. Por otra parte, es necesario equilibrar el conocimiento económicamente pertinente con el conocimiento humano y social pertinente. La educación superior puede ser eficaz y eficiente en términos económicos sin ser socialmente pertinente. Es necesaria la pertinencia académica y la social.

\section{REFERENCIAS}

Brunner, J. J. (1992). América Latina, cultura y modernidad. Consejo Nacional para la Cultura y las Artes.

Calderón Serna, H. D. J., \& González Agudelo, E. M. (2006). Acerca de dónde enseñaron Sócrates, Platón y Aristóteles o sobre el silencio en los espacios dialogantes. UNI-PLURI/VERSIDAD, 6(1), 1-7. http://bibliotecadigital.udea.edu.co/ bitstream/10495/3232/1/CalderonHader_2006_AcercaEnsenanzaSocrates.pdf

Chuaqui J., Benedicto. (2002). Acerca de la historia de las universidades. Revista chilena de pediatría, 73(6), 583-585. https://dx.doi.org/10.4067/S037041062002000600001

Coraggio, J.L. (1995). Las propuestas del Banco Mundial para la educación: ¿sentido oculto o problemas de concepción? En J.L. Coraggio y R.M. Torres, La educación según el Banco Mundial. Miño y Dávila-CEM. https://pdfs.semanticscholar. org/0aa4/b5ce767410593b861f3e6b3769e9e20b749f.pdf

Cúneo, D. (2013). La Reforma Universitaria (1918-1930). Revista historia de la educacion latinoamericana, 15(21), 424-429.

Donald R. W. (1994). La Educación Superior en América Latina. Cuestiones sobre Eficiencia y Equidad. Banco Mundial (Documentos para discusión). 
Funes, P., \& Caldelari, M. (2001). Textos para el pregón, el afiche y el muro: algunas reflexiones" pre-liminares" acerca del Manifiesto Liminar. Universidad de Buenos Aires, Libros del Rojas.

González, E. G. (1987). Los primitivos estatutos y ordenanzas de la Real Universidad de México. Generalitat Valenciana.

González, R. (1990). La obra legislativa de Justiniano y la cristianización del cosmos. Cristianismo y aculturación en tiempos del Imperio Romano, pp.495-518.

Haddad, W. D. (1990). Education and Development: Evidence for New Priorities. World Bank Discussion Papers No. 95. https://files.eric.ed.gov/fulltext/ED326471.pdf

Jaramillo, A. (2016). Atlas Histórico de América Latina y el Caribe: aportes para la descolonización pedagógica y cultural (Tomo 1). UNLa.

Le Goff, Jacques (1999). La Civilización del Occidente Medieval. Paidós.

Marsiske, R. (2010). La Universidad de México: historia y desarrollo. Revista Historia de la Educación Latinoamericana, 8, 11-34. https://www.redalyc.org/ pdf/869/86900802.pdf

Miranda Pacheco, M. (1979). La Autonomía Universitaria en Bolivia; en La Autonomía Universitaria en América Latina. Volumen II. (pp. 81-96). UNAM

Moncada, J. S. (2007). La Universidad: un acercamiento histórico-filosófico. Ideas y Valores, 57(137), 131-147. https://revistas.unal.edu.co/index.php/idval/article/ viewFile/1491/2116

Mora, A. M. (2008). La Universidad de París en el siglo XIII: historia, filosofía y métodos. Revista de estudios sociales, (31), 60-71. https://journals.openedition.org/ revestudsoc/17263

Mundial, B. (Ed.). (1995). La enseñanza superior: las lecciones derivadas de la experiencia. Banco Mundial.

Portantiero, J. C. (1978). Estudiantes y política en América Latina: el proceso de la reforma universitaria, 1918-1938. Siglo XXI.

Psacharopoulos, G., \& Woodhall, M. (1995). Education for development. Oxford University Press.

Pulido, M. L. (2018). Principios educativos de la educación occidental: la Edad Media. Revista Brasileira de Educação, 23, 1-24. https://doi.org/10.1590/s141324782018230035

Rodó, J. E. (1975). Ariel. Espasa Calpe.

Roig, A. A. (1981). Deodoro Roca y el Manifiesto de la Reforma de 1918, en: Arturo Roig, Filosofía, universidad y filósofos en América Latina. UNAM (serie Nuestra América).

Steger. H. A. (1974). Las Universidades en el Desarrollo Social de América Latina. Fondo de Cultura Económica. 
Tamayo de Serrano, C. (2007). The cultural and educational contribution of the Low Middle Ages. Educ.educ, 10(2), 197-213. http://educacionyeducadores.unisabana. edu.co/index.php/eye/article/download/698/781\%3A\%3Apdf

Tünnermann Bernheim, C. (2003). La Universidad ante los Retos del Siglo XXI Universidad Autónoma de Yucatán.

Villareal Ramos, E. (1999). La autonomía universitaria en América Latina: modalidades y proyección social (Doctorado). UNAM.

Winkler, D. R. (1994). La educación superior en América Latina: cuestiones sobre eficiencia y equidad. World Bank. 